\title{
Identifying the Molecular Orientation and Clusters in Liquid-Vapor Interface of 1-Propanol by Time-Delayed Mass Spectrometry
}

\author{
Ziwei Chen ${ }^{\mathrm{a}}$, Cen-Feng Fu ${ }^{\mathrm{a}}$, Ziyuan $\mathrm{Li}^{\mathrm{a}}$, Jie $\mathrm{Hu}^{\mathrm{a}}$, Hao Li ${ }^{\mathrm{a}}$, Jinlong Yang ${ }^{\mathrm{a}, \mathrm{b}}$, and Shan Xi Tian ${ }^{\mathrm{a}, \mathrm{b}, \mathrm{c}, *}$ \\ ${ }^{a}$ Hefei National Laboratory for Physical Sciences at the Microscale and Department of Chemical \\ Physics, ${ }^{b}$ Collaborative Innovation Center of Chemistry for Energy Materials (iChEM), ${ }^{~} \mathrm{Key}$ \\ Laboratory of Surface and Interface Chemistry and Energy Catalysis of Anhui Higher Education \\ Institutes, University of Science and Technology of China, Hefei 230026, China \\ * Corresponding author. E-mail: sxtian@ustc.edu.cn.
}

\section{Contents:}

Section 1. Cluster Distributions Predicted with MD Simulations

Section 2. Cations Produced by Electron Impacts

Section 3. TOF-QMF Tandem Time-Delayed Mass Spectrometry

Section 4. Solvation Energies of the Neutral and Protonated Dimers 


\section{Section 1. Cluster Distributions Predicted with MD Simulations}

Using the GROMACS 4.5.5 package, ${ }^{1}$ we performed the MD simulations with the all-atomic parameters of OPLS-AA force field ${ }^{2}$ for molecular 1-propanol. Initially, a homogenous system of 1-propanol liquid reached its thermodynamic equilibrium at $P=1 \mathrm{~atm}$ and $T=300 \mathrm{~K}$. Then, a 4.0 $\mathrm{nm}(x) \times 4.0 \mathrm{~nm}(y) \times 10.0 \mathrm{~nm}(z)$ rectangular box (consisting of 1264 molecules) was intercepted and set into a $4.0 \mathrm{~nm}(x) \times 4.0 \mathrm{~nm}(y) \times 40.0 \mathrm{~nm}(z)$ rectangular box which was implemented with the periodic boundary condition in all three directions. This system was energy-minimized using the conjugate gradient method. Subsequently, a $10.0 \mathrm{~ns}$ simulation in the NVT ensemble was performed to equalize the system at common pressure $1 \mathrm{~atm}$ but different temperature 250,275 or $300 \mathrm{~K}$, followed with another $5.0 \mathrm{~ns}$ simulation in the $N V T$ ensemble for the data collection. The Berendsen thermostat ${ }^{3}$ was employed to regulate the temperature. The coupling times of 0.2 and 0.5 ps were used for the equilibrium and data collection simulations, respectively. The cutoff distance for van der Waals interactions was $1.5 \mathrm{~nm}$, with a long-range dispersion correction applied for energy. The particle-mesh Ewald (PME) method ${ }^{4}$ was employed to treat Coulomb interactions with a $1.3 \mathrm{~nm}$ cutoff for real-space. All bonds were constrained using P-LINCS algorithm.,

1-propanol clusters are formed or linked with intermolecular HBs. An intermolecular hydrogen bond is defined with the distance between the $\mathrm{H}(-\mathrm{O})$ atom of the HB-donor and the $\mathrm{O}$ atom of the HB-acceptor. This distance must be less than the location of the first peak for the radial O...H-O distribution functions, namely, $1.86,1.88$, and $1.88 \AA$ for the temperatures of 250,275 , and $300 \mathrm{~K}$, respectively. The following figure shows the HB-cluster distributions at 250 and $275 \mathrm{~K}$. The conformers with chain-, ring-, cage- and branch-structures can be found for the trimer and the larger HB clusters.
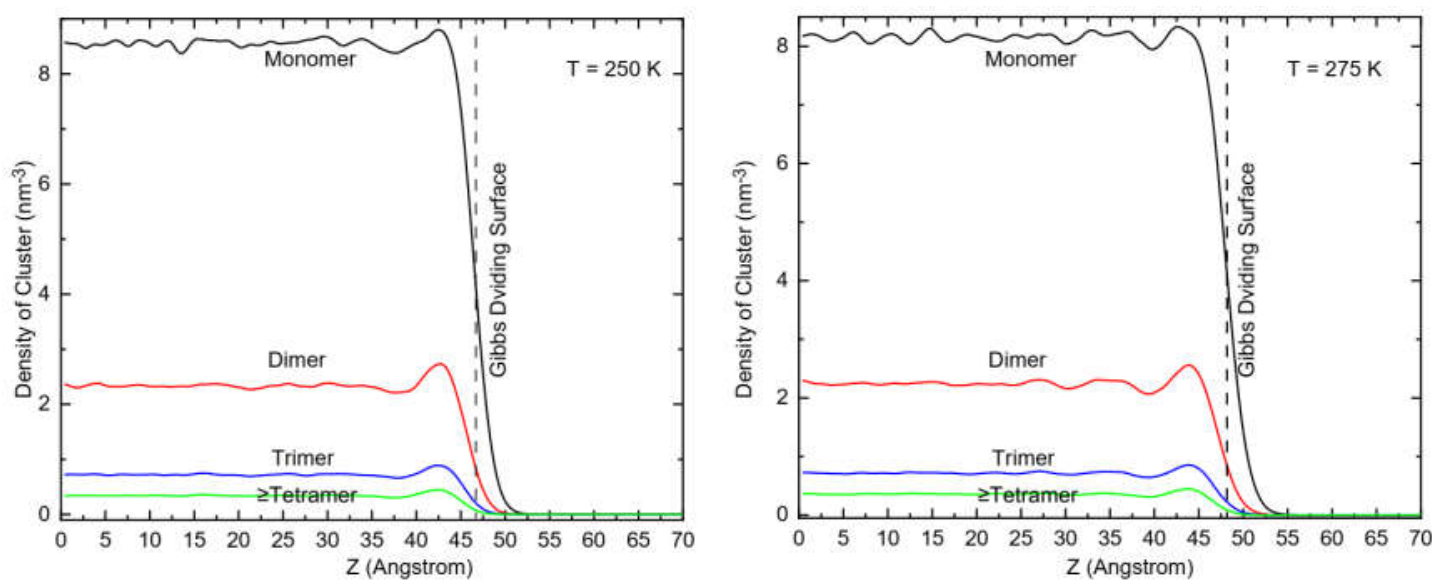

Figure S1. Density distributions of the monomer, dimer, trimer and the larger clusters near the liquid surface of 1-propanol. The results at the temperatures of 250 and $275 \mathrm{~K}$ are shown in the upper and bottom panels, respectively. In each panel, Gibbs dividing surface is denoted with a vertical dashed line.

\section{Section 2. Cations Produced by Electron Impacts}

In the present experiments, the background pressure of the reaction chamber is retained at $2 \times 10^{-4} \mathrm{~Pa}$ 
(the gas-phase experiments) or $9 \times 10^{-3} \mathrm{~Pa}$ (the liquid-beam experiments). Cations produced in the electron-impact dissociative ionization of the gas-phase 1-propanol are assigned in Fig. $\mathrm{S} 2(\Delta \mathrm{t}=0$ $\mu \mathrm{s})$, with reference to the data in the literatures. ${ }^{7,8}$ The relative intensities of some cationic fragments are different from those observed in refs. 7 and 8 , due to the different experimental arrangements, in particular, the different sizes of the ion entrance (or attractor) aperture.

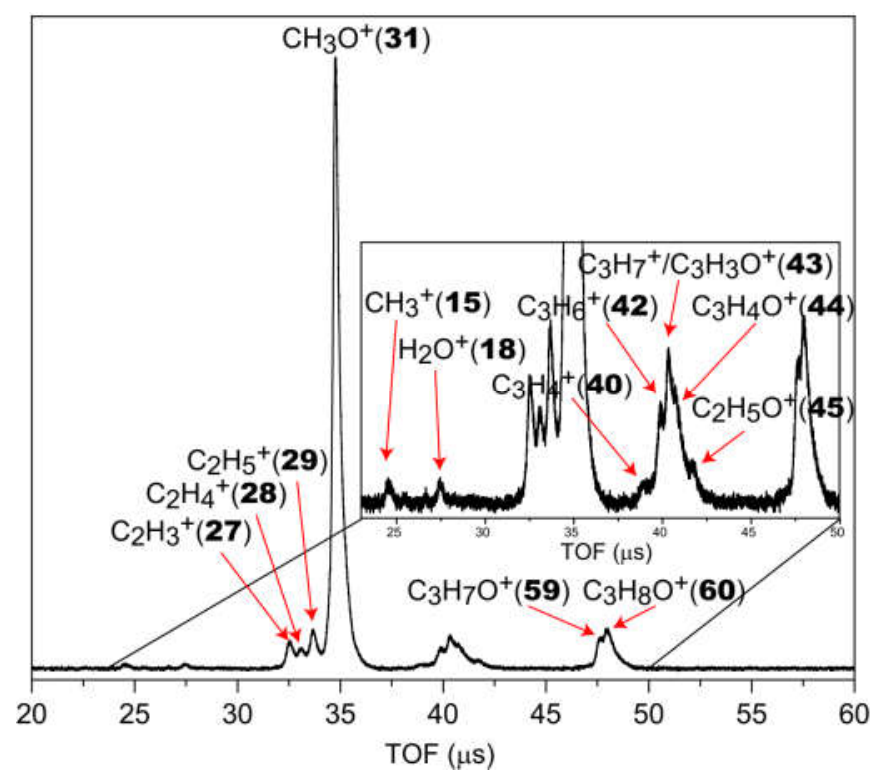

Figure S2. Mass spectrum of the cations produced by $22 \mathrm{eV}$ electron impact ionization of the gasphase 1-propanol at $\Delta \mathrm{t}=0 \mu \mathrm{s}$. The values in the parentheses denote the $\mathrm{m} / \mathrm{z}$ values (in $\mathrm{amu}$ ) of the ionic fragments.

Table S1. The Ionic Fragments Observed in the Gas-Phase and Liquid Experiments.

\begin{tabular}{|r|l|l|l|}
\hline $\mathrm{m} / \mathrm{z}(\mathrm{amu})=15$ & $\mathrm{C} / \mathrm{z}(\mathrm{amu})=55$ & $\mathrm{C}_{3} \mathrm{H}_{3} \mathrm{O}^{+}$ \\
\hline 18 & $\mathrm{H}_{2} \mathrm{O}^{+}$ & 56 & $\mathrm{C}_{3} \mathrm{H}_{4} \mathrm{O}^{+}$ \\
\hline 27 & $\mathrm{C}_{2} \mathrm{H}_{3}{ }^{+}$ & 57 & $\mathrm{C}_{3} \mathrm{H}_{5} \mathrm{O}^{+}$ \\
\hline 28 & $\mathrm{C}_{2} \mathrm{H}_{4}{ }^{+} / \mathrm{CO}^{+}$ & 58 & $\mathrm{C}_{3} \mathrm{H}_{6} \mathrm{O}^{+}$ \\
\hline 29 & $\mathrm{C}_{2} \mathrm{H}_{5}{ }^{+} / \mathrm{CHO}^{+}$ & 59 & $\mathrm{C}_{3} \mathrm{H}_{7} \mathrm{O}^{+}$ \\
\hline 30 & $\mathrm{C}_{2} \mathrm{H}_{6}{ }^{+} / \mathrm{CH}_{2} \mathrm{O}^{+}$ & 60 & $\mathrm{C}_{3} \mathrm{H}_{8} \mathrm{O}^{+}$(monomer) \\
\hline 31 & $\mathrm{CH}_{3} \mathrm{O}^{+}$ & 61 & $\mathrm{C}_{3} \mathrm{H}_{9} \mathrm{O}^{+}$(protonated monomer) \\
\hline 32 & $\mathrm{CH}_{4} \mathrm{O}^{+}$ & 120 & $\mathrm{C}_{6} \mathrm{H}_{16} \mathrm{O}^{+}$(dimer) \\
\hline 39 & $\mathrm{C}_{3} \mathrm{H}_{3}{ }^{+}$ & 121 & $\mathrm{C}_{6} \mathrm{H}_{17} \mathrm{O}^{+}$(protonated dimer) \\
\hline 40 & $\mathrm{C}_{3} \mathrm{H}_{4}{ }^{+} / \mathrm{C}_{2} \mathrm{O}^{+}$ & & \\
\hline 41 & $\mathrm{C}_{3} \mathrm{H}_{5}{ }^{+} / \mathrm{C}_{2} \mathrm{HO}^{+}$ & & \\
\hline 42 & $\mathrm{C}_{3} \mathrm{H}_{6}{ }^{+} / \mathrm{C}_{2} \mathrm{H}_{2} \mathrm{O}^{+}$ & & \\
\hline 43 & $\mathrm{C}_{3} \mathrm{H}_{7}{ }^{+} / \mathrm{C}_{2} \mathrm{H}_{3} \mathrm{O}^{+}$ & & \\
\hline 44 & $\mathrm{C}_{2} \mathrm{H}_{4} \mathrm{O}^{+}$ & & \\
\hline 45 & $\mathrm{C}_{2} \mathrm{H}_{5} \mathrm{O}^{+}$ & & \\
\hline
\end{tabular}


The isomass ions, such as $\mathrm{C}_{2} \mathrm{H}_{4}{ }^{+}$and $\mathrm{CO}^{+}(\mathrm{m} / \mathrm{z}=28 \mathrm{amu})$, could be produced simultaneously in the collisions between the gas-phase (or vaporized) 1-propanol and the 22-eV electrons. However, in Fig. 3, one can find that the corresponding signals (as the part of sub-band b) are enhanced with the increase of the delaying time $(\Delta \mathrm{t})$, while the neighboring ions $\mathrm{CH}_{3} \mathrm{O}^{+}(\mathrm{m} / \mathrm{z}=31 \mathrm{amu})$ and $\mathrm{CH}_{4} \mathrm{O}^{+}$ $(\mathrm{m} / \mathrm{z}=32 \mathrm{amu})$ (sub-band a) in the TOF mass spectra are nearly absent at $\Delta \mathrm{t}=4500 \mathrm{~ns}$. Considering the spatial orientations of the interface molecules (as depicted in Figs. 1A and 3C), as $\Delta t>4500 \mathrm{~ns}$, the ion with $\mathrm{m} / \mathrm{z}=28$ amu should be $\mathrm{C}_{2} \mathrm{H}_{4}{ }^{+}$, rather than $\mathrm{CO}^{+}$.

In the gas-phase experiment, besides the fragment ions, the protonated parent ion $\mathrm{C}_{3} \mathrm{H}_{9} \mathrm{O}^{+}(\mathrm{m} / \mathrm{z}=$ $61 \mathrm{amu})$ is detected and found to reach an intensity maximum around $\Delta \mathrm{t}=1500 \mathrm{~ns}$. As pointed out in our previous study ( 9 , as well as cited therein), a proper delaying time facilitates the production of the protonated monomer via the ion-molecule reaction. However, the production of this protonated ion $\mathrm{C}_{3} \mathrm{H}_{9} \mathrm{O}^{+}$in the liquid-beam experiment shows the different profile in terms of $\Delta \mathrm{t}$, shown with the black circles in Fig. S3. This ion can be quickly produced in the condensed vapor above the liquid surface when $\Delta \mathrm{t}$ is less than $1000 \mathrm{~ns}$, but its collection efficiency is reduced remarkably around $\Delta \mathrm{t}=1000 \sim 3000 \mathrm{~ns}$, because the most $\mathrm{C}_{3} \mathrm{H}_{9} \mathrm{O}^{+}$ions fly away from the small aperture $(\phi 2 \mathrm{~mm})$ of the ion attractor. Around $\Delta \mathrm{t} \sim 5000 \mathrm{~ns}$, the $\mathrm{C}_{3} \mathrm{H}_{9} \mathrm{O}^{+}$ions produced at the liquid surface come out and are detected by the TOF system, finally the ion intensity becomes invariable for $\Delta \mathrm{t}>6000 \mathrm{~ns}$.

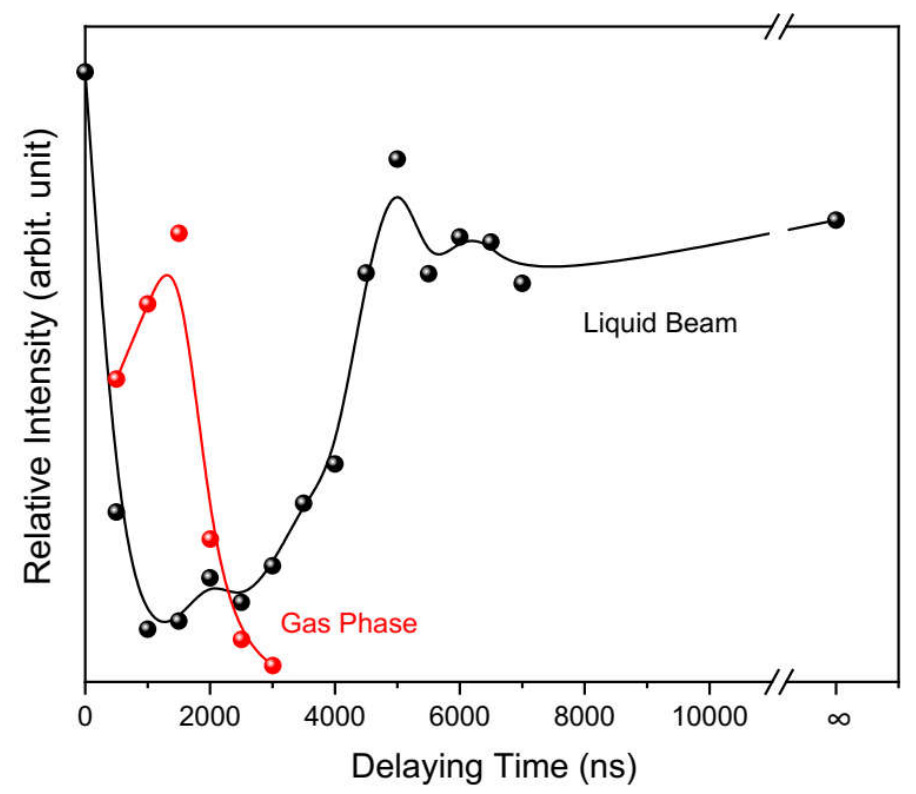

Figure S3. Intensity variances of the protonated propanol ion $\left(\mathrm{C}_{3} \mathrm{H}_{9} \mathrm{O}^{+}\right)$in terms of delaying time. The gas-phase and liquid-beam results are shown with the red and black circles, respectively.

It is noted here, in Fig. S3, the protonated monomer $\mathrm{C}_{3} \mathrm{H}_{9} \mathrm{O}^{+}$produced in the liquid surface was detected with the TOF-QMF tandem time-delayed mass spectrometry. This method is described in the following section.

Section 3. TOF-QMF Tandem Time-Delayed Mass Spectrometry 
Since the ion productions in the liquid-beam experiments are diverse (not only in the different local regions but also at various moments after the electron impact), an arbitrary elongation of the TOF tube (see Fig. 2A) is almost helpless to identify the individual ions. Moreover, the ion production information about the local regions and times could be lost if a reflectron TOF mass spectrometer is utilized. Therefore, we introduced the QMF at the downstream of the TOF tube.

A

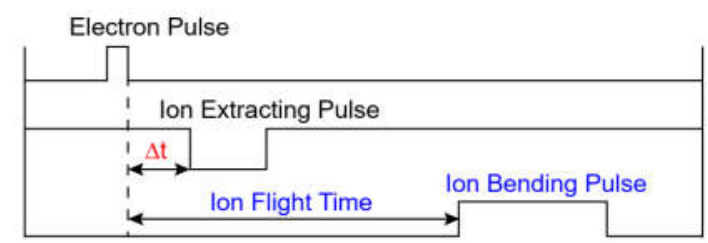

B

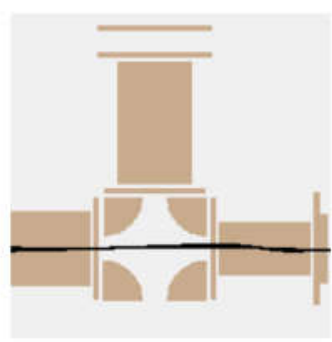

TOF Mode

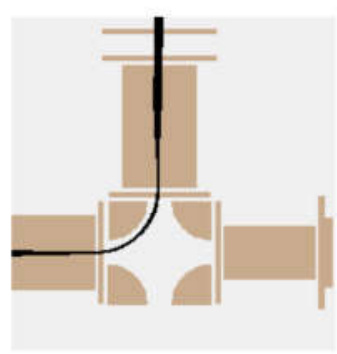

QMF Mode

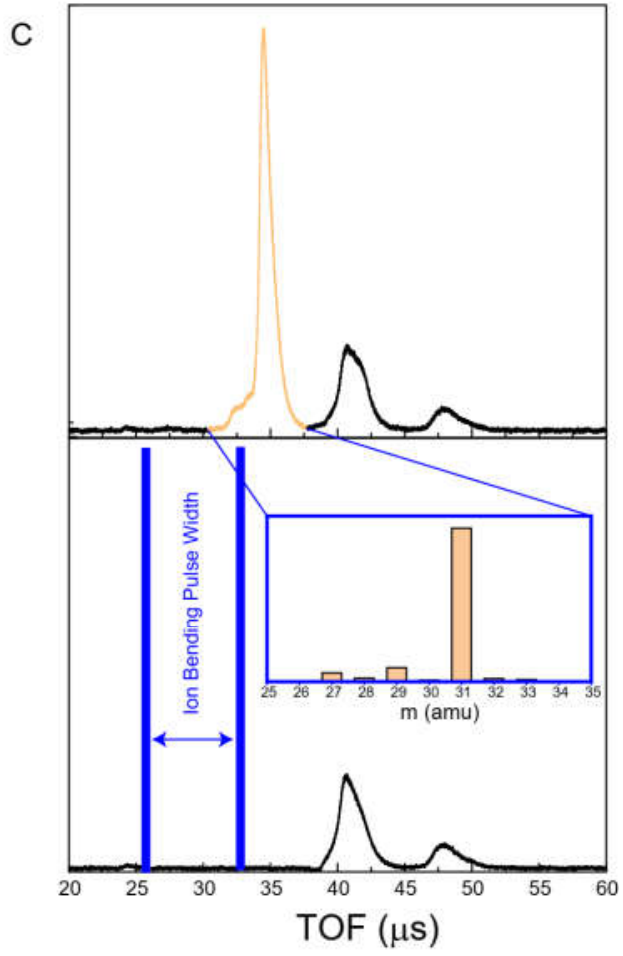

Figure S4. Time pulse sequence (A), two working modes (B) and the selective detection of some ions in the TOF spectra (C). (B) QMF mode can be operated with the continuously and selectively (pulsed) bending conditions. (C) The ions of the main band in the TOF spectrum (upper panel) are selected by applying a bending pulse on the ion bender, and then identified with the QMF (as shown in the inserted spectrum in the bottom panel). This band disappears in the TOF spectrum (bottom panel).

As shown in Fig. S4, the ion bender is working at the pulse mode, which selects the ions in a certain range or band of the TOF mass spectrum for detection. Here the ion bending pulse must be applied in advance, see the blue-bar assignment in the bottom panel of Fig. S4C. Alternatively, the flying trajectories of all ions can be bent by applying a proper DC voltage on the ion bender, thus the all ions are detected with the QMF, instead of the TOF system.

\section{Section 4. Solvation Energies of the Neutral and Protonated Dimers}

Firstly, 100 neutral dimers in different conformations were stochastically selected from the MD simulations (in the last $5.0 \mathrm{~ns}$ ) at the temperature of $275 \mathrm{~K}$. Then, we put the proton to the $\mathrm{O}$ atom of either HB-donor or HB-acceptor in these dimers, thereby we had 317 protonated dimers. Since there are the complicated energy transformations between the translational and internal energies, 
the internal energy of the evaporating species is usually high. Therefore, although the conformational structure of the neutral or protonated dimer in above case should be significantly different from its equilibrium structure (corresponding to its local minimum on the potential energy surface), we did not optimize the geometrical parameters of these stochastically selected dimers.

To get the solvation energy of the isolate dimer, we calculated the energy difference between a single dimer (the neutral or protonated) solvated in the 1-propanol liquid and a free dimer in vacuum, by using the solvent reaction field method with the SMD model. ${ }^{10}$ To simulate the evaporation processes from the different regions in the liquid, we utilized various values of the dielectric permittivity of solvent, $2.000,4.000,6.000,8.000,10.000,12.000,14.000,16.000,18.000$ and 20.524, where 20.524 was the permittivity value of the pure liquid (bulk) of 1-propanol and 1.000 was the reference value of vacuum. The other parameters in the SMD model were fixed. Above energetic calculations were performed at the B3LYP/6-31+G(d,p) level. ${ }^{11}$ In Fig. 4B, the statistic errors were given according to the deviations from the averaged value of the solvation energy for all conformers.

\section{References:}

1. Hess, B.; Kutzner, C.; Der Spoel, D. V.; Lindahl, E. J. Chem. Theory Comput. 2008, 4, 435.

2. Jorgensen, W. L.; Maxwell, D. S.; Tiradorives, J. J. Am. Chem. Soc. 1996, 118, 11225.

3. Berendsen, H. J. C.; Postma, J. P. M.; van Gunsteren, W. F.; Dinola, A.; Haak, J. R. J. Chem. Phys. 1984, 81, 3684.

4. Essmann, U.; Perera, L.; Berkowitz, M. L.; Darden, T.; Lee, H.; Pedersen, L. G. J. Chem. Phys. 1995, 103, 8577.

5. Hess, B.; Bekker, H.; Berendsen, H. J. C.; Fraaije, J. G. E. M. J. Comput. Chem. 1997, 18, 1463.

6. Hess, B. J. Chem. Theory Comput. 2008, 4, 116.

7. Pires, W. A. D.; Nixon, K. L.; Ghosh, S.; Neves, R. F. C.; Duque, H. V.; Amorim, R. A. A.; Jones, D. B.; Blanco, F.; Garcia, G.; Brunger, M. J. Int. J. Mass Spectrom. 2017, 442, 32.

8. Rejoub, R.; Morton, C. D.; Lindsay, B. G.; Stebbings, R. F. J. Chem. Phys. 2003, 118, 1756.

9. Chen, L.; Chen, Z.; Li, Z.; Hu, J.; Tian, S. X. Rev. Sci. Instrum. 2018, 89, 103102.

10. Marenich, A. V.; Cramer, C. J.; Truhlar, D. G. J. Phys. Chem. B 2009, 113, 6378.

11. Frisch, M. et al., Gaussian 09, Revision D.01. Gaussian, Inc., Wallingford CT, 2009. 